Tropical Journal of Pharmaceutical Research January 2016; 15 (1): 95-99

ISSN: $1596-5996$ (print); 1596-9827 (electronic)

(C) Pharmacotherapy Group, Faculty of Pharmacy, University of Benin, Benin City, 300001 Nigeria.

All rights reserved.

Available online at http://www.tjpr.org

Original Research Article

http://dx.doi.org/10.4314/tjpr.v15i1.13

\title{
Wortmannin as Targeted Therapeutic Agent for the Treatment of Triple-Negative Breast Cancer
}

\author{
Jian $\mathrm{Li}^{1,2,3}$, Fei Liu ${ }^{3}$, Yang Liư ${ }^{4}$, Jia-Jun $\mathrm{Du}^{1,2}$ and Qi Liu ${ }^{1 *}$ \\ ${ }^{1}$ Institute of Oncology, ${ }^{2}$ Department of Thoracic Surgery, Provincial Hospital Affiliated to Shandong University, Jinan 250021, \\ ${ }^{3}$ Department of Breast Surgery, ${ }^{4}$ Department of General Surgery, Taian City Central Hospital, Taian 271000, China \\ *For correspondence: Email: qiliu6655@gmail.com; Tel/Fax: 0086-021-65161782
}

Received: 22 May 2015

Revised accepted: 10 December 2015

\begin{abstract}
Purpose: To investigate the inhibitory effect of wortmannin on inhibition of BT-20 and BT-474 breast cancer cells in Athymic nu/nu mice model.

Methods: Forty Athymic nu/nu mice were randomly assigned to 4 groups of 10 each, namely, BT-20 control, BT-20 treatment, BT-474 control and BT-474 treatment groups. The mice were injected with 2.5 $\times 10^{5} B T-20$ and BT-474 cells under anesthesia. Those in the treatment groups were given wortmannin $(7 \mathrm{mg} / \mathrm{kg}$ ) in DMSO daily intraperitoneally whereas the animals in control groups received an equal volume of DMSO for 21 days after the cancer attained palpable stage. Western blot analysis was carried out using enhanced chemiluminescence reagent while Protean IEF cell unit was used for 1-D electrophoresis.

Results: The results showed a significant decrease in the growth of the tested cancer cell lines on treatment with wortmannin at $7 \mathrm{mg} / \mathrm{kg}$ daily for 21 days. The volume of tumor in the treatment group was reduced to $42.72 \pm 9.45$ compared to $79.43 \pm 17.11 \mathrm{~mm}^{3}$ in the control group after 21 days treatment $(p<0.005)$. It also changed the expression of microRNA in BT-20 cells. Exposure of BT-20 cells to wortmannin for $24 \mathrm{~h}$ resulted in the altered expression of proteomes. Wortmannin treatment increased the expression of miRs including miR 19a/b, 22, 29b/c, 181c/d, 195 and 663. Western blot data showed increase in the expression of NME1 (NM23 H1) and reduction in the expression of vimentin after treatment with wortmannin.

Conclusion: Wortmannin can be of benefit in the treatment of human breast cancer.
\end{abstract}

Keywords: Wortmannin, Vimentin, Tumor growth, Expression of microRNA, Proteomes

Tropical Journal of Pharmaceutical Research is indexed by Science Citation Index (SciSearch), Scopus, International Pharmaceutical Abstract, Chemical Abstracts, Embase, Index Copernicus, EBSCO, African Index Medicus, JournalSeek, Journal Citation Reports/Science Edition, Directory of Open Access Journals (DOAJ), African Journal Online, Bioline International, Open-J-Gate and Pharmacy Abstracts

\section{INTRODUCTION}

Breast carcinoma is a challenging health issue at present affecting one out of every eight women, especially in US [1]. It is estimated that about 20 $\%$ of the patients with primary breast cancer rapidly develop distant metastases leading to higher mortality rates [2]. The median survival period for breast cancer patients is around three years [2]. Breast cancer has been found commonly in women and its proportion in men is very low [3]. Triple negative breast cancer
(TNBC) comprises a group of heterogeneous diseases which are prevalent among African and American women and is more aggressive compared to other cancers [4-6]. It has been reported that TNBC spreads rapidly to distant tissues and leads to mortality within very short time span of the disease [4]. Therefore, the discovery of molecules which target the TNBC is desired for its treatment.

The commonly used chemotherapeutic agents for cancer treatment are antibiotics belonging to 
the anthracycline, bleomycin, actinomycin, mitomycin and aureolic acid families [7]. Among these families, anthracyclines exhibit promising anti-tumor activities through the suppression of topoisomerase II $[8,9]$. Another important natural isolate wortmannin from the fungus Talaromyces wortmanni has been shown to act as inhibitor of signal transduction pathways targeting 3 kinase (PI3K) activity [10]. Targeting signal transduction cascades by involvement of bioactive compounds is believed to be a promising strategy for carcinoma therapy [11]. The present study was designed to investigate the effect of wortmannin on breast carcinoma inhibition, miR expression and proteome expression.

\section{EXPERIMENTAL}

\section{Materials}

\section{Cell lines and culture}

Human breast carcinoma cell lines, BT-20 and BT-474 were purchased from the Riken Bioresource Center (Tsukuba, Japan). The cells were cultured in cultured Dulbecco's modified Eagle's medium/F-12 (DMEM/F-12) (Wako) supplemented with $10 \%$ fetal bovine serum (FBS) (Cambrex, Walkersville, MD, USA).

\section{Drug}

Wortmannin was isolated from the fungus, Talaromyces wortmanni, using solvent extraction followed by column chromatography in $10 \%$ methanol and chloroform.

\section{Xenograft model of tumorigenesis}

Athymic nu/nu 6-week-old female mice (Harlan Sprague-Dawley) were fed irradiated sterile food and water. The mice were acclimatized to the laboratory environment one week before the experiment was started. The animals were randomly assigned to 4 groups with 10 each, BT20 control, BT-20 treatment, BT-474 control and BT-474 treatment groups. The animals were injected with BT-20 or BT-474 cells $\left(2.5 \times 10^{5}\right)$ in the mammary fat pad under anesthesia. The animals in the treatment groups were given wortmannin (7 $\mathrm{mg} / \mathrm{kg})$ in DMSO daily intraperitoneally whereas the animals in control groups received equal volume of DMSO for 21 days after the cancer attained palpable stage. During the treatment period volume of cancerous mass was calculated after every 2 days by measuring the tumor size with digital calipers. After the completion of the treatment, the animals were sacrificed to extract the tumors, uterus, liver, and lungs. The tissues were immediately fixed in formalin and stored under cold conditions using liquid nitrogen. The liquid nitrogen frozen samples were then used for other analyses.

The animal experiments were performed according to the rules of the ethical committee of the Weifang People's Hospital, No. 207 Guangwen Street, Kuiwen District, Weifang, Shandong. All measures were taken to minimize suffering in the animal.

\section{Western blot analysis}

The cells after treatment with wortmannin were washed with phosphate-buffered saline (PBS) and lysed in lysis buffer containing aprotinin (10 $\mathrm{mg} / \mathrm{mL}$ ), leupeptin (10 mg/mL) (ICN Biomedicals, Inc., Asse Relegem, Belgium) and phenylmethylsulfonyl fluoride (Sigma-Aldrich). The proteins were separated on SDS-PAGE, loaded on PVDF and treated with primary antibodies. After incubation the membrane was incubated with secondary antibodies conjugated to horseradish peroxidase. The blots were examined using enhanced chemiluminescence reagent (ELPS, Seoul, Korea).

\section{Proteomics analysis}

The cells, after treatment with wortmannin or normal saline for $24 \mathrm{~h}$, were subjected to $2 \mathrm{D}$ electrophoresis. Protean IEF cell unit (BioRad, Hercules, CA, USA) was used for 1-D electrophoresis and the proteins were separated using Precast $11 \mathrm{~cm}$ IPG strips. BioRad Criterion electrophoresis cell system was employed for 2$D$ electrophoresis and Gel Doc XR image system (BioRad) was used for analysis of stained gels. The scanned gels were analyzed with PDQuest software (version 8.01).

\section{Statistical analysis}

All the experiments were performed in triplicate. Student t-test or analysis of variance (ANOVA) was used for statistical analysis. Differences were considered statistically significant at $p<$ 0.05 .

\section{RESULTS}

\section{Inhibition of breast carcinoma growth}

The animals in both treatment and control groups were administered carcinoma cells, BT-20 or BT474 along with reduced growth factor matrigel (Fig 1A,B). When the tumor attained palpable stage, animals in the treatment group were given wortmannin $(7 \mathrm{mg} / \mathrm{kg} / \mathrm{day})$ and those of control group received an equal volume of normal saline. 
It was observed that the volume of tumor in treatment group was markedly small compared to control group. The tumor volume in the treatment and control groups were $42.72 \pm 9.45$ and $79.43 \pm 17.11 \mathrm{~mm}^{3}$, respectively after the completion of the treatment period.

\section{Effect of wortmannin on the miRnome}

The BT-20 cells on exposure to wortmannin for $24 \mathrm{~h}$ showed prominent changes in the expression of miRNA whereas no such changes were observed in untreated control cells. Wortmannin treatment significantly enhanced the expression of some of the miRs including $\mathrm{miR}$ 19a/b, 22, 29b/c, 181c/d, 195 and 663 (Figure 2A). In addition wortmannin treatment inhibited the expression of some of the miRs including, 193a 5p, 197, 224, 486 5p, and 542 5p (Figure 2B).

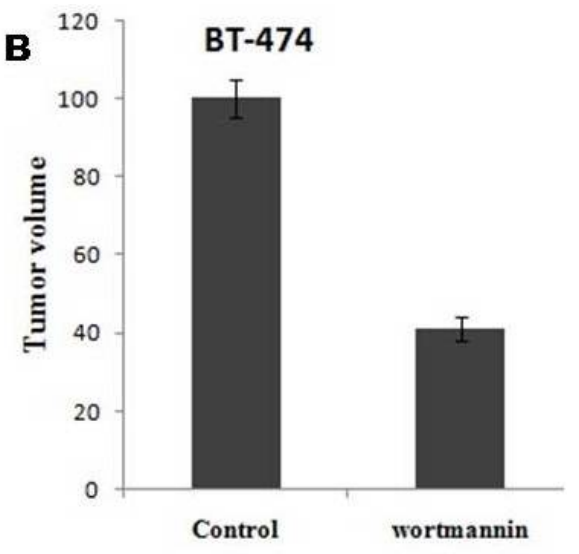

Figure 1: Suppression of tumor growth by wortmannin in breast carcinoma. The mice were administered (A) BT20 or (B) BT-474 and after palpable tumor growth injections of wortmannin $(7 \mathrm{mg} / \mathrm{kg})$ or saline were given to animals
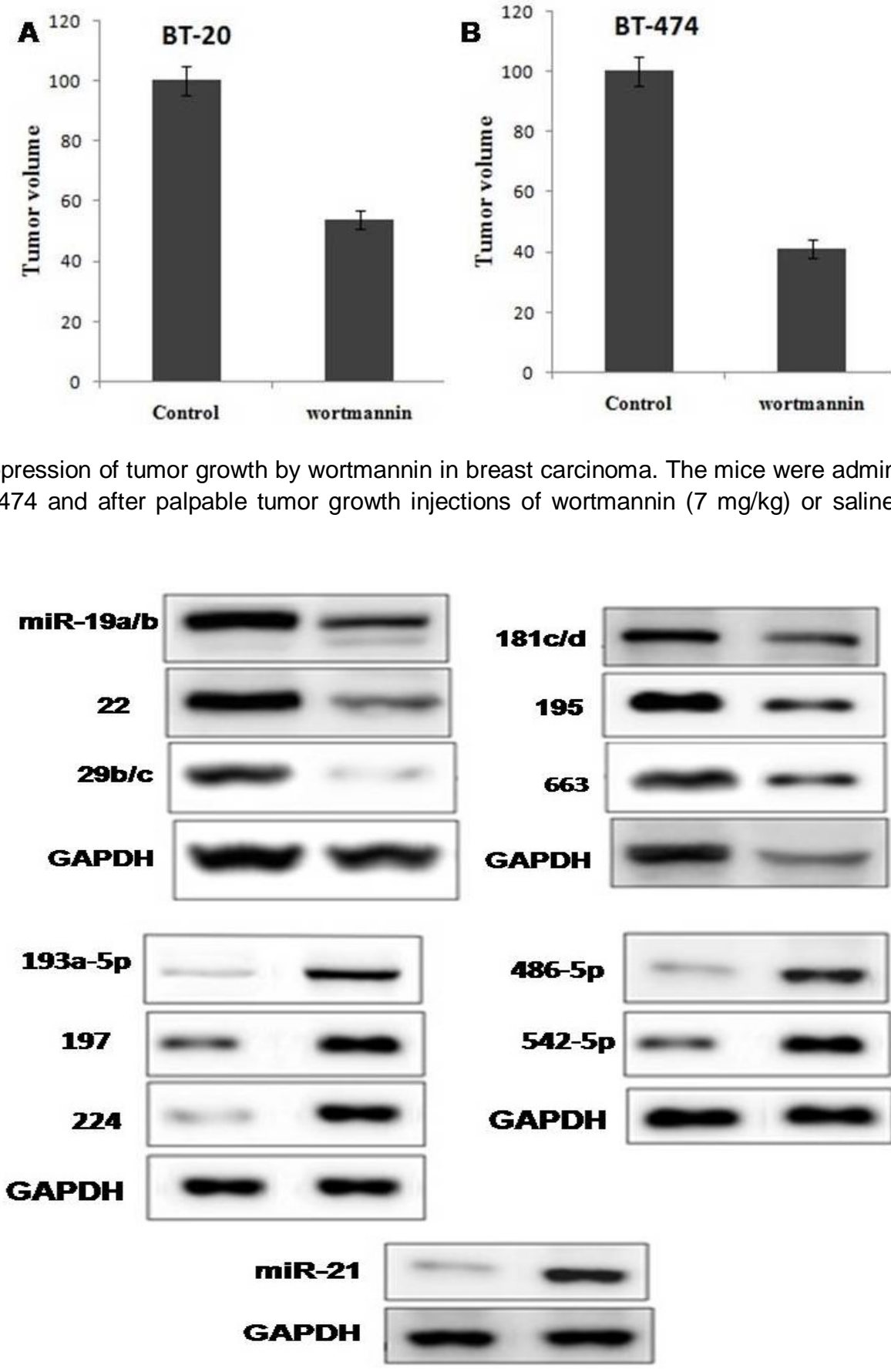

Figure 2: Effect of wortmanninon microRNA expression in BT-20 cells after $24 \mathrm{~h}$ 
Wortmannin changes the proteome of BT-20 breast carcinoma cells

Exposure of BT-20 cells to wortmannin for $24 \mathrm{~h}$ induced changes in the expression of proteomes. The results from Western blot analysis showed increase in the expression of NME1 (NM23 H1) by wortmannin treatment (Figure 3). The expression of vimentin was significantly decreased by treatment with wortmannin (Figure $3)$.

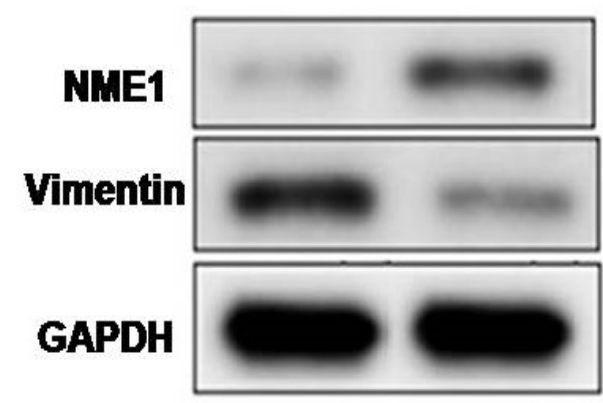

Figure 3: Effect of wortmannin on the expression of tumor genes

\section{DISCUSSION}

In cancerous tissues miR expression shows changes which are known to be associated with increase in tumor growth, resistance to drugs and spread of cancer cells [16-18]. The results obtained in the present study showed that wortmannin induces expression of miRs and thus acts as suppresser of tumor growth. It has been reported that miRs exhibits anti-carcinoma effect on tumor growth by interfering with the expression of Jun B and Jun D [19]. miR 19 suppresses the expression of tissue factor which is involved in the progress of tumors [20]. The results from the present study revealed increase in the expression of tumor suppressor genes on exposure to wortmannin. Studies have demonstrated that miR 193a $5 p$ genes play an important role in the progression of tumor growth [21]. In the present study it was observed that the expression of the genes was inhibited by exposure to wortmannin.

It is reported that miR 21 gene is responsible for inducing resistance to drugs resulting in poor tumor prognosis rate [22,23]. Wortmannin induced inhibition of these genes and thus prevented the development of resistance to drugs. A surface marker found during change of epithelial cells to mesenchymal cells is overexpressed in breast cancer cells [15]. The expression of vimentin is significantly enhanced following treatment with wortmannin. Therefore, wortmannin suppresses the growth of tumors in breast cancer cells.

\section{CONCLUSION}

Wortmannin inhibits the growth of breast carcinoma cells via change in expression of miR. Thus, wortmannin can be used for the treatment of breast cancer.

\section{REFERENCES}

1. American Cancer Society, 2010. Breast Cancer Statistics: Breast cancer overview: how many women get breast cancer, 2010.

2. Stevanovic A, Lee $P$, Wilcken $N$. Metastatic breast cancer. Aust Fam Physician 2006; 35: 309312.

3. Anderson WF, Jatoi I, Tse J, Rosenberg PS. Male breast cancer: a population based comparison with female breast cancer. J Clin Oncol 2010; 28: 232239.

4. Reis Filho JS, Tutt AN. Triple negative tumours: a critical review. Histopathology 2008; 52: 108118.

5. Bauer KR, Brown M, Cress RD, Parise CA, Caggiano V. Descriptive analysis of estrogen receptor $(E R)$ negative, progesterone receptor (PR) negative, and HER2 negative invasive breast cancer, the so called triple negative phenotype: a population based study from the California cancer registry. Cancer 2007; 109: 1721 1728.

6. Dent R, Trudeau M, Pritchard KI, Hanna WM, Kahn HK, Sawka CA, Lickley LA, Rawlinson E, Sun P, Narod SA. Triple negative breast cancer: clinical features and patterns of recurrence. Clin Cancer Res 2007; 13: 4429 4434.

7. Cragg GM, Newman D J, Weiss RB. Coral reefs, forests, and thermal vents: the worldwide exploration of nature for novel antitumor agents. SeminOncol 1997; 24: 156163.

8. Monica B, Rosalba F, M. Evelina B, Giovanni C.In vivo site specificity and human isoenzyme selectivity of two topoisomerase II poisoning anthracyclines. Cancer Res 2000; 60: 3770-3776.

9. Patrick $Y$. Major microbial diversity initiative recommended. Am SocMicrobiol News 1997; 63: 417421.

10. Cadenas ME, Sandfrison A, Cutler NS.Signal transduction cascades as targets for therapeutic intervention by natural products. Trends Biotechnol 1998; 16: 427-433.

11. Adjei AA. Signal transduction pathway targets for anticancer drug discovery. Curr Pharmaceut Design 2000; 6: 361-378.

12. Patel JB, Appaiah HN, Burnett RM, Bhat-Nakshatri $P$, Wang G, Mehta R, Badve S, Thomson MJ, Hammond $S$, Steeg $P$, Liu $Y$, Nakshatri $H$. Control of EVI 1 oncogene expression in metastatic breast cancer cells through microRNA miR 22. Oncogene 2011; 30: 1290 1301. 
13. Bonci D. Micro RNA 21 as therapeutic target in cancer and cardiovascular disease. Recent Pat Cardiovasc Drug Discov 2011; 5: 156161.

14. Russell RL, Pedersen AN, Kantor J. Relationship of nm23 to proteolytic factors, proliferation and motility in breast cancer tissues and cell lines. Br J Cancer 1998; 78: 710717.

15. Kokkinos MI, Wafai R, Wong MK, Newgreen DF, Thompson EW, Waltham M. Vimentin and epithelial mesenchymal transition in human breast cancer observations in vitro and in vivo. Cells Tissues Organs 2007; 185: 191203.

16. Farazi TA, Spitzer Jl, Morozov P, Tuschl T. miRNAs in human cancer. J Pathol 2011; 223: 102115.

17. Winter J, Diederichs S. MicroRNA biogenesis and cancer. Methods Mol Biol 2011; 676: 322.

18. Allen KE, Weiss GJ. Resistance may not be futile: microRNA biomarkers for chemoresistance and potential therapeutics. Mol Cancer Ther 2011; 9: 3126 3136.
19. TiliE, Michaille JJ, Adair B. Resveratrol decreases the levels of miR 155 by upregulating miR 663, a microRNA targeting JunB and JunD. Carcinogenesis 2011; 31: 15611566.

20. Zhang X, Yu H, Lou JR. MicroRNA 19 (miR 19) regulates tissue factor expression in breast cancer cells. J Biol Chem 2011; 286: 14291435.

21. Ory B, Ramsey MR, Wilson C. A microRNA dependent program controls p53 independent survival and chemosensitivity in human and murine squamous cell carcinoma. J Clin Invest 2011; 121: 809820.

22. Mei M, Ren $Y$, Zhou $X$. Downregulation of miR 21 enhances chemotherapeutic effect of taxol in breast carcinoma cells. Technol Cancer Res Treat 2011; 9: 77 86.

23. Gong C, Yao Y, Wang Y, Liu B, Wu W, Chen J, Su F, Yao $H$, Song $E$. Up regulation of miR 21 mediates resistance to trastuzumab therapy for breast cancer. $J$ Biol Chem 2011; 286: 1912719137. 